\title{
Models of competition between one for-profit and one nonprofit firm
}

\author{
Petra Brhlikova
}
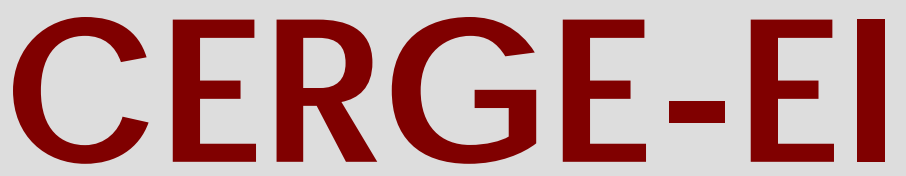

Charles University

Center for Economic Research and Graduate Education Academy of Sciences of the Czech Republic 


\title{
Models of competition between one for-profit and one nonprofit firm*
}

\author{
Petra Brhlikova ${ }^{\dagger}$
}

\begin{abstract}
To study the coexistence of two different ownership forms within an industry, I develop a simple model of competition between one forprofit and one nonprofit firm. The two firms have different objectives and face different constraints due to their choice of ownership status. Assuming heterogenous consumers I derive quality-price bundles provided by the two firms and their market shares under various conditions.

Pro analýzu koexistence dvou různych vlastnických forem v rámci jednoho sektoru vytvařím model souteže mezi jednou ziskovou a jednou neziskovou firmou. Tyto firmy mají různé účelové funkce a platí pro ně různá omezení. Za předpokladu heterogenních spotřebitelů odvozuji kvalitu a cenu produktů dodávaných danými firmami a jejich podíl na trhu.
\end{abstract}

Keywords: Nonprofit firm, for-profit firm, monopoly, duopoly, mixed industry

JEL Classification: L31, L1, D42, D43

*I would like to thank Marc Bilodeau, Andreas Ortmann, Avner Shaked, and Richard Steinberg for helpful comments. This research was started during a mobility stay at IUPUI Economics Department, whose support is gratefully acknowledged.

†CERGE-EI, Charles University, Prague and the Academy of Sciences of the Czech Republic, P.O.Box 882, Politickych veznu 7, 11121 Prague 1, Czech Republic, phone: +420 224005 227, e-mail: petra.brhlikova@cerge-ei.cz. 


\section{Contents}

1 Introduction 4

$\begin{array}{llr}2 & \text { Model } & 7\end{array}$

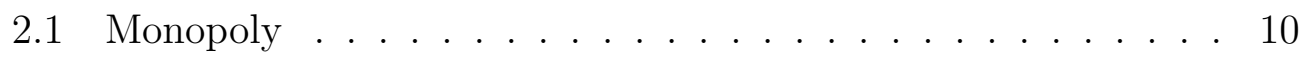

2.1.1 For-profit (FP) monopoly . . . . . . . . . . . 11

2.1.2 Nonprofit (NP) monopoly . . . . . . . . . . . . . . 12

2.1.3 Comparison: FP versus NP monopoly . . . . . . . . . 13

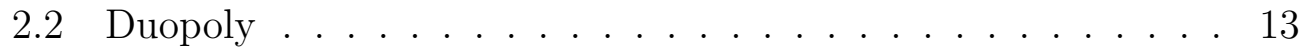

2.2.1 FP duopoly - simultaneous choice . . . . . . . . . 15

2.2.2 FP duopoly - sequential choice . . . . . . . . . 16

2.2.3 Comparison: FP duopoly - simultaneous vs. sequential choice ..................... 17

2.2.4 NP duopoly - simultaneous choice . . . . . . . . 18

2.2.5 NP duopoly - sequential choice . . . . . . . . . 20

2.2.6 Comparison: NP duopoly - simultaneous vs. sequential choice . . . . . . . . . . . . . . . 20

2.2.7 Comparison: FP versus NP duopoly . . . . . . . . . 20

2.2.8 Mixed duopoly - simultaneous choice . . . . . . . . . 21

2.2.9 Mixed duopoly - sequential choice . . . . . . . . . 23

2.2.10 Comparison: mixed duopoly - simultaneous vs. sequential choice . . . . . . . . . . . . . . 24

2.2.11 Comparison: mixed duopoly vs. FP and NP duopoly . 25 
3.1 Inefficiency in the NP firm . . . . . . . . . . . . . . 27

3.2 Market size . . . . . . . . . . . . . . . . . . . 28

3.3 Mixed duopoly - modified sequential game . . . . . . . . . . 29

4 Conclusion $\quad 32$

5 References $\quad 34$

6 Appendix 36

$6.1 \mathrm{FP}$ and NP monopoly . . . . . . . . . . . . . 36

6.2 FP duopoly - simultaneous choice . . . . . . . . . . . 36

6.3 FP duopoly - sequential choice . . . . . . . . . . . . . 37

6.4 NP duopoly - simultaneous choice . . . . . . . . . . . . . . 38

6.5 NP duopoly - sequential choice . . . . . . . . . . . . . . 39

6.6 Mixed duopoly - simultaneous choice . . . . . . . . . . . . 40

6.7 Mixed duopoly - sequential choice . . . . . . . . . . . . . . . 42

6.8 Mixed duopoly - modified sequential game . . . . . . . . . . 43 


\section{Introduction}

The focus of this paper is competition between nonprofit and for-profit firms, i.e. firms characterized by different ownership forms. The coexistence of nonprofit and for-profit firms is common in many service industries such as health care, education, theatrical production, orchestras, as well as sport and recreational clubs (Rose-Ackerman 1996). Although the theoretical and empirical research analyzes the distinctive nature and performance of these two types of firms, usually it treats them separately, ignoring the interaction between their production decisions. ${ }^{1}$

Nonprofit organizations are given several advantages including exemption from paying certain taxes and regulatory breaks (Facchina et al. 1993). They can, moreover, receive donations that have the effect of subsidies. In return, nonprofits, through non-distribution and reasonable compensation constraints, may not distribute profits to managers. Instead, they are expected to use their profits for enhancing quality or lowering price. In the present paper I focus on quality enhancements although I also discuss cases when a nonprofit firm decreases price to increase its market share.

Interestingly, nonprofits coexist and compete with their for-profit counterparts in fields such as health care, education, museums, and theatrical pro-

\footnotetext{
${ }^{1}$ A theoretical model by Hirth (1999) and recent empirical research on the competition in health care (e.g., Grabowski and Hirth 2003, Kessler and McClellan 2001) are exceptions.
} 
duction. The dominant theory of nonprofits, formulated by Hansmann (1980), says that nonprofit organizations are an institutional response to information asymmetries in markets where quality and effort are adjustable. Because of the nondistribution and reasonable compensation constraints, nonprofits do not have incentives to exploit market asymmetries. They, therefore, deliver higher quality than their for-profit counterparts.

Based on the information asymmetry framework, Hirth (1999) builds a model of competition between for-profit and nonprofit nursing homes. He focuses on markets where the quality of care is either high or low. Consumers have identical preferences for the quality of care and want to purchase only high quality. Consumers, however, differ in the information they have about the quality of care delivered by a particular provider. Informed consumers observe both quality and price, while uninformed consumers know only price and the ownership form of a provider (nonprofit or for-profit). There are two types of nonprofit firms, honest and so-called 'for-profits-in-disguise'. ${ }^{2}$ Hirth analyzes equilibria under three different levels of enforcement of the nondistribution constraint. In the equilibrium with strict enforcement (which is my focus here), uninformed consumers patronize nonprofit homes, which deliver higher quality and charge a higher price than for-profit homes. ${ }^{3}$

\footnotetext{
${ }^{2}$ The term 'for-profit-in-disguise' was introduced by Weisbrod (1988) to represent profitmotivated entrepreneurs who enter the nonprofit sector to exploit the advantages bestowed on nonprofit institutions.

${ }^{3}$ For specific values of parameters it is even possible that the quality produced in the for-profit sector equals the quality of nonprofit products but the price of the for-profit product is lower than the price of nonprofit product. Hirth also analyzes situations when the non-distribution constraint is moderately or weakly enforced. In such cases nonprofit
} 
The empirical evidence does not support the suggested sorting of poorly informed consumers into the nonprofit sector (Grabowski and Hirth 2003, Ortmann and Schlesinger 2003). The evidence in Clotfelter (1992), for example, seems to favor the heterogeneous tastes story (Weisbrod 1975). According to this theory, nonprofits emerge in situations when the market and the state fail to deliver the whole spectrum of quality demanded. In the present study, I build on the heterogeneous tastes story and analyze a full information model.

Hirth (1999) sketches a full information model where consumers have different preferences for quality. Nonprofit firms choose a market niche corresponding to their objectives, leaving the residual demand to for-profit firms. Specifically, if nonprofits want to deliver high quality, for-profit firms would take the low quality niche. Hirth suggests that if nonprofits would be eliminated, for-profit firms would replace them, still providing the optimal quality spectrum. However, this is not true if the costs of producing high quality are too high. The model presented here shows that for-profit firms might not be willing to produce as high a quality as nonprofit firms would.

Monopolistic competition between identical for-profit firms was studied by Shaked and Sutton (1982), among others. I analyze competition between for-profit and nonprofit firms. Throughout the paper I assume positive production costs that are independent of quantity and monotonically increasing in quality. ${ }^{4}$ The cost functions of for-profits and nonprofits are identical. 
Given these cost configurations, I answer the following questions: How do differences in objectives and constraints affect quality-price pairs supplied by competing firms? What are the market shares of competing firms?

The structure of the paper is as follows. To better understand the impact of different objectives for product price and quality I discuss first the two cases with only one firm in the market: a single for-profit firm and a single nonprofit firm (Section 2.1). Then I proceed with models of duopoly, for-profit versus for-profit firm (Section 2.2.1-3), nonprofit versus nonprofit firm (Section 2.2.4-2.2.7), and finally mixed industry (Section 2.2.8-11). For duopoly cases two different structures of the game are analyzed. In sequential choice firms first choose quality of production and then decide the price. In simultaneous choice, both firms choose their prices and qualities at the same time. In the third section, I summarize the results obtained and discuss several generalizations of the model. The fourth section concludes. Computational details are described in the Appendix.

\section{Model}

The demand side is populated by a continuum of heterogeneous consumers. Specifically, consumers differ in their taste for quality, although they have the same wealth, $w$. Consumers can consume two goods: a public good and a private good. The public good is assumed to be a nonrival excludable public 
good (a play, concert, art exhibition, etc.) and is provided by the nonprofit firm or the for-profit firm, or both. It is characterized by quality, $q$, and price, $p \leq w$. Consumers differ in their preferences for the quality of the public good. Their heterogeneity is modelled by a taste parameter, $\theta$, that is uniformly distributed over the interval $\langle 0,1\rangle$. According to their preferences consumers buy one or zero (non-buying option) units of the public good. The private good can be purchased outside the market of our interest. It is characterized by quantity, $x$, and its price, $p_{x}$, is set equal to one. The utility function, $U_{i}\left(\theta_{i} q, x\right)=\theta_{i} q+x$, is increasing in the consumption of both goods, public and private.

Consumer $i$ 's optimization problem is

$\operatorname{Max}_{j, x} \theta_{i} q_{j}+x$ s.t. $p_{j}+x=w$,

where $j=n, f, z$ stands for the $(q, p)$-bundles offered. The nonprofit firm offers $\left(q_{n}, p_{n}\right)$, the for-profit firm produces $\left(q_{f}, p_{f}\right)$, and $\left(q_{z}, p_{z}\right)=(0,0)$ represents the non-buying option (denoted by $z$ as a zero quality). Note that consumers do not choose along a continuous budget constraint, but are offered only three $(q, p)$-bundles to choose from (see Figure 1). The for-profit and nonprofit bundle is determined by firms' maximization problems described below.

The public good, as mentioned, is supplied by the nonprofit (NP) and forprofit (FP) firm. The NP firm is assumed to maximize quality and is re- 


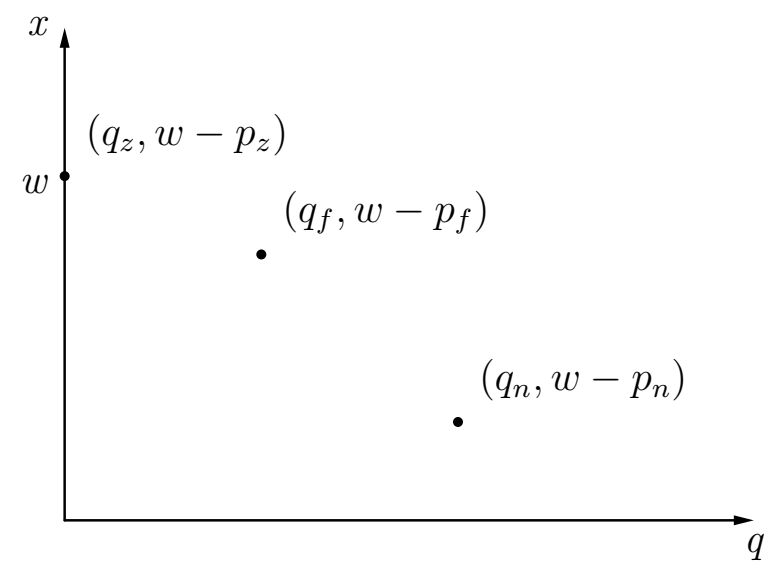

Figure 1: The three quality-price bundles offered

stricted from distributing profits. ${ }^{5}$ This means that the NP firm invests its profits in further quality enhancement or alternatively, decreases price to increase its market share. The realization of profits and investments in quality or price subsidization happen in the same period, i.e. the NP firm, in fact, faces a zero-profit constraint. The FP firm maximizes profit.

The costs of producing the public good are described by $c(q)$, which is an increasing function in $q$ with increasing $\mathrm{MC}$ (i.e. it is convex in $q$ ). As mentioned, the public good is assumed to be an excludable and nonrival good whose costs are independent of the number of consumers. I.e. the costs, $c(q)$, incurred are in fact the fixed costs of producing quality $q$. For the NP firm's production costs I assume that all the advantages mentioned (tax exemption,

\footnotetext{
${ }^{5}$ An alternative objective function of the NP firm is a combination of quality and quantity (Newhouse 1970) or as in Hansmann (1981), who focuses on art performing firms, quality, audience, or budget maximization. The focus of the present paper is quality maximization, although equilibrium for a more general case when the NP firm maximizes a linear combination of quality and quantity is also discussed.
} 
regulatory breaks, and donations) are aggregated in a subsidy, $s$. Thus, NP firm's costs are $(1-s) c(q)$. Throughout the paper I use mainly quadratic cost functions that have linearly increasing marginal costs. ${ }^{6}$

The maximization problems of the two types are as follows:

NP: $\operatorname{Max}_{q_{n}, p_{n}} q_{n}$ s.t. $t_{n} p_{n}=(1-s) c\left(q_{n}\right)$

FP: $\operatorname{Max}_{q_{f}, p_{f}} t_{f} p_{f}-c\left(q_{f}\right)$,

where $t_{n}$ and $t_{f}$ represent shares of consumers that purchase the public good from NP and FP respectively. These shares are, as I will show later, in fact functions of the products' characteristics, $q_{n}, p_{n}, q_{f}$, and $p_{f} . t_{z}$, analogically, represents the share of consumers that prefer the non-buying option. Thus the condition on market shares is $t_{n}+t_{f}+t_{z}=1$.

\section{$2.1 \quad$ Monopoly}

In the following two sections, I analyze cases when there is a single firm in the market, either one nonprofit or one for-profit firm. I'm interested in quality-price pairs that would be produced by the two different firms. I put aside, for now, the question why there is a single firm in the market and I also ignore the problem of potential entrants.

\footnotetext{
${ }^{6}$ This is to keep the analysis as simple as possible. Towards an exploration of the robustness of my results for quadratic cost functions, I use in Section 3 also shifted quadratic and cubic cost function.
} 


\subsubsection{For-profit (FP) monopoly}

In this section I study the case when only the FP product and the non-buying option, $\left(q_{z}, p_{z}\right)$, are available to consumers. To determine demand for the FP product we need to characterize a pivotal consumer, i.e. the consumer who is indifferent between consuming the FP product and not buying the public good at all. Formally, $U\left(\tilde{\theta} q_{f}, w-p_{f}\right)=U\left(\tilde{\theta} q_{z}, w-p_{z}\right)$. Using the utility function specified above, this equation characterizes the pivotal consumer through her taste parameter, $\tilde{\theta}=\frac{p_{f}}{q_{f}}$.

The FP firm supplies its product to all consumers with a sensitivity param-

eter of at least $\tilde{\theta}$, and its market share is $1-\frac{p_{f}}{q_{f}}$. The FP firm chooses $q_{f}$ and $p_{f}$ to optimize

$\operatorname{Max}_{q_{f}, p_{f}}\left(1-\frac{p_{f}}{q_{f}}\right) p_{f}-q_{f}^{2}$.

The FP firm chooses quality such that $M R=M C$ and price such that $M R=0$. The solution to this problem, given the assumption on uniformly distributed tastes for quality, is $\left(q_{f}, p_{f}\right)=(0.1250,0.0625)$. The FP firm supplies its product to the upper segment of the market and serves one half of the market, i.e. consumers with a sensitivity parameter of at least $1 / 2$. The profit of the FP firm is 0.0156 . 


\subsubsection{Nonprofit (NP) monopoly}

In this case consumers opt between the NP bundle, $\left(q_{n}, p_{n}\right)$, and the nonbuying option. The pivotal consumer is characterized by $\tilde{\theta}=\frac{p_{n}}{q_{n}}$.

The NP's market share is $1-\tilde{\theta}=1-\frac{p_{n}}{q_{n}}$. The NP firm chooses the $\left(q_{n}, p_{n}\right)$ pair that maximizes quality given the nondistribution constraint:

$\left(1-\frac{p_{n}}{q_{n}}\right) p_{n}=(1-s) q_{n}^{2}$.

The solution for the NP firm's maximization problem, given the assumption on uniformly distributed tastes for quality, is $\left(q_{n}, p_{n}\right)=\left(\frac{1}{4(1-s)}, \frac{1}{8(1-s)}\right)$ with $\left(q_{n}, p_{n}\right)=(0.2500,0.1250)$ for $s=0$. Both $q_{n}$ and $p_{n}$ are increasing in $s$. For all $s \in\langle 0,1\rangle$ the NP firm serves half of the market (the upper segment), i.e. consumers with $\theta_{i} \geq 1 / 2$ buy the NP product while those who value the quality of the public good less prefer the non-buying option.

With the NP firm maximizing a linear combination of quality and market share, i.e. $\max _{q_{n}, p_{n}} b q_{n}+(1-b)\left(1-\frac{p_{n}}{q_{n}}\right)$ s.t. $\left(1-\frac{p_{n}}{q_{n}}\right) p_{n}=(1-s) q_{n}^{2}$, where $b \in\langle 0,1\rangle$, an interior solution exists only for $b \in(1 / 2,1\rangle$. For a lower weight on quality maximization and a correspondingly higher weight on market share maximization, there is only a corner solution $\left(q_{n}, p_{n}\right)=(0,0)$. Intuitively, the market share of the NP firm is maximized at $p_{n}=0$ (in such a case its market share equals 1). At zero price the NP firm's revenue is zero for any market share, thus to satisfy the zero profit constraint it can produce only zero quality. When quality maximization becomes more important the 
NP firm finances the production of higher quality by increasing its price. Its market share, however, declines. ${ }^{7}$

\subsubsection{Comparison: FP versus NP monopoly}

Comparing the FP and NP monopoly outputs derived in the previous two sections, both monopolies supply to the upper half of the market. The quality delivered and price charged by the NP firm is, however, higher than in the FP case. Specifically for $s=0$ we have $\left(q_{n}, p_{n}\right)=\left(2 q_{f}, 2 p_{f}\right)$. The nonprofit firm, under the assumption of quality maximization, invests its potential profit and available subsidies only into quality enhancement. It does not subsidize price to increase market share. Conversely, for increased quality consumers' willingness to pay is higher and the NP firm is able to increase price. If the NP firm would also give positive weight to market share maximization, it would start to subsidize price in order to increase market share.

\subsection{Duopoly}

In this section I proceed with analyzing firms' choice of $(q, p)$-pairs when there are two firms in the market. I start with competition between two identical FP firms, then turn to the competition between two identical NP firms, and finally focus on the coexistence of one FP and one NP firm. In all three cases I analyze a one-stage game ("simultaneous choice") and a

\footnotetext{
${ }^{7}$ Equilibria for $s=0$ and $b>1 / 2$ are presented in Section 6.1.
} 
two-stage game ("sequential choice"). In the one-stage game, the two firms simultaneously choose their qualities and prices. In the two-stage game firms are assumed to choose qualities simultaneously in the first stage. In the second stage they choose prices given optimal qualities. This seems to be a reasonable assumption since price can be adjusted more easily than the quality of production.

Independently of the ownership form of competing firms there are two different qualities at different prices provided (plus the non-buying option is available) in the duopoly. ${ }^{8}$ The three bundles are similar to those depicted in Figure 1 (the $\left(q_{h}, w-p_{h}\right)$ bundle would replace the NP bundle from Figure 1 and the $\left(q_{l}, w-p_{l}\right)$ bundle would replace the FP bundle). The market is divided into three segments: consumers buying the high-quality product $\left(q_{h}\right)$, consumers buying the low-quality product $\left(q_{l}\right)$, and consumers who do not buy the public good at all (non-buying option).

The taste for quality is again assumed to be uniformly distributed. Then the sensitivity parameter of the consumer indifferent between the high-quality and low-quality product, $\bar{\theta}$, and of the consumer indifferent between the low and zero quality, $\underline{\theta}$, are the following:

$U\left(\bar{\theta} q_{h}, w-p_{h}\right)=U\left(\bar{\theta} q_{l}, w-p_{l}\right) \Rightarrow \bar{\theta}=\frac{p_{h}-p_{l}}{q_{h}-q_{l}}$

$U\left(\bar{\theta} q_{l}, w-p_{l}\right)=U\left(\bar{\theta} q_{z}, w-p_{z}\right) \Rightarrow \underline{\theta}=\frac{p_{l}-p_{z}}{q_{l}-q_{z}}=\frac{p_{l}}{q_{l}}$.

The market share of the high-quality producer is, therefore, $t_{h}=1-\bar{\theta}$ and the

\footnotetext{
${ }^{8}$ The reasoning why this is so for all types of duopolies studied here is given in other sections.
} 
low-quality producer supplies a $t_{l}=(\bar{\theta}-\underline{\theta})$-fraction of the market. The rest of the consumers, $\underline{\theta}$, prefer the non-buying option to both the high-quality and low-quality products.

\subsubsection{FP duopoly - simultaneous choice}

The two FP firms simultaneously choose quality and price to maximize their profits. Their optimization problems are as follows: ${ }^{9}$

$F P_{h}: \max _{q_{h}, p_{h}}\left(1-\frac{p_{h}-p_{l}}{q_{h}-q_{l}}\right) p_{h}-q_{h}^{2}$

$F P_{l}: \max _{q_{l}, p_{l}}\left(\frac{p_{h}-p_{l}}{q_{h}-q_{l}}-\frac{p_{l}}{q_{l}}\right) p_{l}-q_{l}^{2}$.

Note that in equilibrium the two FP producers offer different qualities at different prices. Producing the same quality and charging equal prices can not be an equilibrium since both producers have incentives either to slightly increase quality or slightly decrease price in order to gain all the consumers who want to purchase the public good. Producing the same quality and charging different prices (or alternatively offering different qualities at a single price) is not optimal for the producer with a higher price (or lower quality), who earns zero or negative profit (zero revenue while costs are greater than or equal to zero). Thus, two FP firms offer two different qualities at different prices, i.e. enjoy a locally monopolistic position and earn positive profits.

\footnotetext{
${ }^{9}$ In this problem I assume that the market size is 1 . In Section 6, I derive a solution to a more general problem, where a positive parameter $a$ represents the market size.
} 
The equilibrium is $\left(q_{h}, q_{l}, p_{h}, p_{l}\right)=(0.12,0.04,0.05,0.01) .{ }^{10}$ Corresponding market shares and profits are: $t_{h}=0.54, t_{l}=0.27, \Pi_{h}=0.01$, and $\Pi_{l}=0.0005$. Thus the firm producing high quality delivers slightly lower quality and charges a lower price than the FP monopoly. It, however, serves more than one half of the market while the FP and NP monopolies serve exactly one half of the market. The firm producing low quality serves more than one quarter of the market. The two firms do not supply to the whole market, because a positive share of consumers prefers the non-buying option to products offered by the two firms. ${ }^{11}$ Both firms earn positive profits.

\subsubsection{FP duopoly - sequential choice}

In this section it is assumed that producers decide about their choice variables in two stages. First they simultaneously choose qualities to maximize their profits. Then, given optimal qualities, they choose optimal prices.

Similarly to the simultaneous choice, different qualities and different prices are chosen by the two FP firms. The choice of the same quality would lead to Bertrand competition in the second stage. As a result firms would earn negative profits equal to fixed costs. If they choose different qualities, profits

\footnotetext{
${ }^{10}$ First order conditions and the analytical solution are in Section 6. In the case of the FP duopoly, the simultaneous choice and also the sequential choice have two asymmetric equilibria in which one or the other firm produces high quality. There exists also a symmetric equilibrium that I do not specify here, in which the two firms play a mixed strategy.

${ }^{11}$ In Shaked and Sutton (1982) the two top firms cover the whole market since the consumer with the lowest taste for quality has strictly positive preferences for quality.
} 
are strictly positive. The choice of the same price when qualities are different is not optimal since the firm with lower quality loses all its customers.

To solve the problem I start by analyzing the second stage - simultaneous choice of optimal prices. Given optimal $q_{h}$ and $q_{l}$ producers set prices to optimize profits:

$F P_{h}: \max _{p_{h}}\left(1-\frac{p_{h}-p_{l}}{q_{h}-q_{l}}\right)-q_{h}^{2}$

$F P_{l}: \max _{p_{l}}\left(\frac{p_{h}-p_{l}}{q_{h}-q_{l}}-\frac{p_{l}}{q_{l}}\right)-q_{l}^{2}$.

This is equivalent to optimizing their revenues since production costs are treated as constant at this stage (fixed costs of producing a certain quality level). Optimal prices are $p_{h}^{*}\left(q_{h}, q_{l}\right)=\frac{2 q_{h}\left(q_{h}-q_{l}\right)}{4 q_{h}-q_{l}}$ and $p_{l}^{*}\left(q_{h}, q_{l}\right)=\frac{q_{l}\left(q_{h}-q_{l}\right)}{4 q_{h}-q_{l}} \cdot{ }^{12}$

In the first stage, producers choose optimal qualities given optimal prices $p_{h}^{*}\left(q_{h}, q_{l}\right)$ and $p_{l}^{*}\left(q_{h}, q_{l}\right)$ :

$F P_{h}: \max _{q_{h}} \frac{4 q_{h}^{2}\left(q_{h}-q_{l}\right)}{\left(4 q_{h}-q_{l}\right)^{2}}-q_{h}^{2}$

$F P_{l}: \max _{q_{l}} \frac{q_{h} q_{l}\left(q_{h}-q_{l}\right)}{\left(4 q_{h}-q_{l}\right)^{2}}-q_{l}^{2}$.

The equilibrium is $\left(q_{h}, q_{l}, p_{h}, p_{l}\right)=(0.13,0.02,0.05,0.01)$, with $t_{h}=0.53, t_{l}=$ $0.26, \Pi_{h}=0.01$, and $\Pi_{l}=0.0008$.

\subsubsection{Comparison: FP duopoly - simultaneous vs. sequential choice}

Table 1 summarizes the results of the two previous sections

\footnotetext{
${ }^{12}$ See Section 6 for computational details.
} 


\begin{tabular}{|c|c|c|c|c|c|c|c|c|}
\hline Choice & $q_{h}$ & $q_{l}$ & $p_{h}$ & $p_{l}$ & $t_{h}$ & $t_{l}$ & $\Pi_{h}$ & $\Pi_{l}$ \\
\hline sim & 0.1242 & 0.0364 & 0.0474 & 0.0069 & 0.5395 & 0.2698 & 0.0101 & 0.0005 \\
seq & 0.1267 & 0.0241 & 0.0538 & 0.0051 & 0.5250 & 0.2625 & 0.0122 & 0.0008 \\
\hline
\end{tabular}

Table 1: FP duopoly - simultaneous and sequential choice

The two FP firms are better off when they optimize the choice of quality and price in two stages. Prices are chosen in the same way in both cases but there is larger quality differentiation in the sequential game. The market share served in the sequential game is smaller than in the simultaneous game and profits earned by the two firms are higher. This is due to the additional information the firms have about qualities actually chosen in the first stage. Knowing that they have an opportunity to adjust prices to the chosen qualities in the second stage firms choose a better 'location' in the market in the first stage. The optimal 'location' choice corresponds to maximal differentiation. It increases the monopolistic power of the two firms in their 'locations' and firms can exploit consumers' willingness to pay.

\subsubsection{NP duopoly - simultaneous choice}

Similarly to the FP duopoly in Section 2.2.1, the two NP firms simultaneously choose their qualities and prices. The NP's objective is quality maximization rather than profit maximization. The NP firms, in addition, face the zero profit constraint. The qualities offered by the two NP firms are expected to be, therefore, higher than qualities produced by two FP firms. This is true 
even in the case of zero subsidy. ${ }^{13}$ Optimization problems of the two NP firms are as follows

$N P_{h}: \max _{q_{h}, p_{h}} q_{h}$ s.t. $\left(1-\frac{p_{h}-p_{l}}{q_{h}-q_{l}}\right) p_{h}=q_{h}^{2}$

$N P_{l}: \max _{q_{l}, p_{l}} q_{l}$ s.t. $\left(\frac{p_{h}-p_{l}}{q_{h}-q_{l}}-\frac{p_{l}}{q_{l}}\right) p_{l}=q_{l}^{2}$.

As in the FP duopoly, two different qualities at different prices are produced by two NP firms. Rather than profit, the NP firms maximize the quality of their products. The quality offered by the NP monopoly is not feasible when there are two NP firms. The production costs of two units of such a high quality are twice as high as the production costs of one unit, while the revenue is the same. This means negative profits for both NP firms. A quality they could together produce is half of that produced by the NP monopoly. It can not be, however, the equilibrium outcome since both firms have an incentive to increase price that corresponds to higher quality. Thus, two NP firms, like FP firms, produce two different qualities and charge different prices.

Specifically, the equilibrium is $\left(q_{h}, q_{l}, p_{h}, p_{l}\right)=(0.2133,0.0533,0.0853,0.0107) .{ }^{14}$

\footnotetext{
${ }^{13}$ In this section I assume that $s=0$. A strictly positive subsidy would lead to higher qualities offered by the two firms. They are, however, expected to proportionally move toward higher quality if they have the same cost structure. In reality, it might be the case that $s$ is different for the two NP firms. For instance, the NP firm producing high quality most probably receives larger donations because consumers preferring high quality have higher willingness to pay while they pay a price equal to the willingness to pay of the pivotal consumer. Hansmann (1981) argues that a big part of contributions is received from those who attend to performance. Donations then correspond to voluntary price discrimination. This is true also for colleges and universities whose donations from alumni can be conceptualized as deferred fee payments. In the present paper I, nevertheless, ignore consumers' opportunities to donate.

${ }^{14}$ Similarly to the FP duopoly, there are again two asymmetric equilibria with both firms in the market, in which one or the other firm produces high quality and one symmetric
} 
The corresponding market shares are $t_{h}=0.5333, t_{l}=0.2667$, and profits of the two firms are zero due to the zero profit constraint $\left(\Pi_{h}=\Pi_{l}=0\right)$.

\subsubsection{NP duopoly - sequential choice}

In sequential choice, NP firms first optimize with respect to quality and then, knowing the optimal qualities, they choose prices. Prices are, however, automatically determined by qualities through the zero-profit constraint. NPs in fact, have no choice in the second stage and sequential choice leads to the same solution as simultaneous choice. ${ }^{15}$

\subsubsection{Comparison: NP duopoly - simultaneous vs. sequential choice}

The equilibria for simultaneous and sequential choice with two NP firms are the same.

\subsubsection{Comparison: FP versus NP duopoly}

In the FP duopoly sequential choice leads to a larger quality differentiation. In contrast, the quality differentiation is not attractive to two NP firms that aim to maximize quality. Increasing the top quality means moving toward equilibrium (not specified here) in which the NP firms play a mixed strategy. There are, however, two asymmetric equilibria with only one firm in the market, in which one or the other NP firm delivers the NP monopoly outcome.

${ }^{15}$ For completeness, first order conditions and analytical solution are in Section 6.5. 
the NP monopoly output that does not allow a lower quality to exist in the market.

In the NP duopoly, the qualities offered are higher than in the FP duopoly. ${ }^{16}$ The market share is slightly lower than in the FP case: 0.80 compared to 0.81.

\subsubsection{Mixed duopoly - simultaneous choice}

In the previous two sections I examined the segmentation of the market when there are two producers of the same type. In this section I analyze the possible coexistence of one NP and one FP firm within an industry. Recall that the NP has to satisfy the nondistribution constraint (=zero-profit constraint) and is assumed to maximize quality. In addition, the NP firm has a cost advantage due to the availability of subsidies (tax exemption, regulatory breaks, donations) stemming from its NP status. The FP firm is assumed to maximize profit.

In the mixed duopoly it is not reasonable for the FP firm to choose the same quality as the NP firm. Since the NP firm aims to break even, for the FP firm to choose the same quality would imply zero (if $s=0$ ) or negative (if

\footnotetext{
${ }^{16}$ To compare top the qualities in simultaneous choice of two FP firms to two NP firms starting from FP's quality, the NP firm has to satisfy the zero profit constraint, thus it can invest the FP's profit (0.01) into quality enhancement. This allows it to increase quality from 0.12 to approximately 0.16 . The increased quality positively affects consumers' willingness to pay and the NP firm is able to increase price and thus enhance quality further.
} 
$s>0)$ profit. Moreover, similar to the NP duopoly case, the same quality produced by two firms is significantly lower than the quality produced by the NP monopoly. The NP firm in the mixed duopoly, therefore, has an incentive to increase quality. Thus, two different qualities at different prices are offered also in the mixed duopoly with the higher quality being provided by the NP firm.

The above argument also rules out the case of the FP catering to the top end of the market and the NP producing a lower quality. The FP firm would produce the top quality only if it is a profitable option. The NP firm can, however, produce the same quality at a lower price than the FP has to charge. Alternatively, the NP firm can produce a higher quality than the FP firm at a price equal to the FP price. In both cases, consumers previously served by the FP firm would now prefer the NP product. The FP firm would be forced to produce a lower quality than the NP firm.

The two maximization problems are the following:

NP: $\operatorname{Max}_{q_{n}, p_{n}} q_{n}$ s.t. $\left(1-\frac{p_{n}-p_{f}}{q_{n}-q_{f}}\right) p_{n}=(1-s) q_{n}^{2}$

FP: $\operatorname{Max}_{q_{f}, p_{f}}\left(\frac{p_{n}-p_{f}}{q_{n}-q_{f}}-\frac{p_{f}}{q_{f}}\right) p_{f}-q_{f}^{2}$.

First order conditions and a general solution can be found in Section 6.6. Specifically, if $s=0$, the two firms choose in equilibrium the following qualities and prices: $\left(q_{n}, q_{f}, p_{n}, p_{f}\right)=(0.2299,0.0337,0.1019,0.0075)$. The corresponding market shares and profits are $t_{n}=0.5190, t_{f}=0.2595$, and 
$\Pi_{n}=0, \Pi_{f}=0.0008$.

\subsubsection{Mixed duopoly - sequential choice}

In this section I analyze the competition between one NP and one FP firm when they decide about qualities and prices in two stages. First, they simultaneously choose qualities. Second, knowing the chosen quality levels, both its own and the rival's, they set prices. The FP firm maximizes profit in both stages while the NP firm chooses optimal quality and then optimal price to maximize quality such that the zero profit constraint is satisfied. ${ }^{17}$

Similarly to the simultaneous case, there are two different qualities offered at different prices and the NP firm produces high quality while the FP firm delivers low quality. Starting with the analysis of the second stage the two maximization problems are as follows:

NP: $\operatorname{Max}_{p_{n}} q_{n}$ s.t. $\left(1-\frac{p_{n}-p_{f}}{q_{n}-q_{f}}\right) p_{n}=(1-s) q_{n}^{2}$

FP: $\operatorname{Max}_{p_{f}}\left(\frac{p_{n}-p_{f}}{q_{n}-q_{f}}-\frac{p_{f}}{q_{f}}\right) p_{f}-q_{f}^{2}$.

Assuming that the NP's constraint is binding the optimal prices are $p_{n}^{*}\left(q_{n}, q_{f}\right)=\frac{2 q_{n}\left(q_{n}-q_{f}\right)}{4 q_{n}-q_{f}}$ and $p_{f}^{*}\left(q_{n}, q_{f}\right)=\frac{q_{f}\left(q_{n}-q_{f}\right)}{4 q_{n}-q_{f}}$. Using the optimal prices in the first stage the two firms solve

NP: $\operatorname{Max}_{q_{n}} q_{n}$ s.t. $4\left(q_{n}-q_{f}\right)=(1-s)\left(4 q_{n}-q_{f}\right)^{2}$

\footnotetext{
${ }^{17}$ An alternative problem where the NP firm first maximizes quality (unconstrained optimization) and then chooses price satisfying the zero-profit constraint is discussed in Section 3.
} 
FP: $\operatorname{Max}_{q_{f}} \frac{q_{n} q_{f}\left(q_{n}-q_{f}\right)}{\left(4 q_{n}-q_{f}\right)^{2}}-q_{f}^{2}$.

The equilibrium for $s=0$ is $\left(q_{n}, q_{f}, p_{n}, p_{f}\right)=(0.2344,0.0272,0.1067,0.0062)$.

The corresponding market shares and profits are $t_{n}=0.5149, t_{f}=0.2575$, and $\Pi_{n}=0, \Pi_{f}=0.0009$.

\subsubsection{Comparison: mixed duopoly - simultaneous vs. sequential choice}

First, there is a smaller product differentiation in simultaneous choice than in sequential choice in the mixed duopoly. Recall that larger differentiation in the sequential game was present in the FP duopoly but impossible in the NP duopoly. In the mixed duopoly, product differentiation coincides with producers' incentives since the NP firm wants to increase quality and the FP firm wants to increase its profit. It can exploit consumers' willingness to pay more the more different the NP product is.

When one FP and one NP coexist, the NP firm produces quality (0.2299 in simultaneous choice and 0.2344 in sequential choice) that is close to the NP monopoly output (0.2500) and serves more than half of the market. The FP firm provides much lower quality, serves slightly more than one quarter of the market, and earns positive profit.

The equilibria for positive subsidy ${ }^{18}$ available to the NP firm and the case

\footnotetext{
${ }^{18}$ Equilibria for simultaneous choice are computed for $s \in\langle 0,0.9\rangle$ (see Section 6.6). The lowest values of subsidy (0.1 and 0.2) characterize commercial NP firms while higher subsidies characterize donative NP firms. Hansmann (1981, citing Baumol and Bowen
} 
when the market size is doubled (i.e. $a=2$ ) are shown in Section 6.6. A positive subsidy means a comparative advantage for the NP firm, which is able to produce a higher quality. The subsidy, however, also helps the FP firm which is, after the NP's move toward a higher quality, able to increase its price and earn a higher profit. Note that the FP quality is decreasing with the subsidy given to the NP firm. The FP firm wants to enlarge product differentiation, which results in a higher profit.

\subsubsection{Comparison: mixed duopoly vs. FP and NP duopoly}

To emphasize the differences between quality-price bundles offered under various combinations of ownership types Table 2 summarizes the equilibria of simultaneous quality-price choices.

\begin{tabular}{|c|c|c|c|c|c|c|c|c|}
\hline Type & $q_{h}$ & $q_{l}$ & $p_{h}$ & $p_{l}$ & $t_{h}$ & $t_{l}$ & $\Pi_{h}$ & $\Pi_{l}$ \\
\hline$h=F P, l=F P$ & 0.12 & 0.04 & 0.05 & 0.01 & 0.54 & 0.27 & 0.0101 & 0.0005 \\
$h=N P, l=N P$ & 0.21 & 0.05 & 0.09 & 0.01 & 0.53 & 0.27 & 0.0000 & 0.0000 \\
$h=N P, l=F P$ & 0.23 & 0.03 & 0.10 & 0.01 & 0.52 & 0.26 & 0.0000 & 0.0008 \\
\hline
\end{tabular}

Table 2: FP duopoly, NP duopoly, and mixed duopoly

$q_{h}\left(q_{l}\right)$ and $p_{h}\left(p_{l}\right)$ represent high (low) quality and prices. $t_{h}, t_{l}, \Pi_{h}$ and $\Pi_{l}$ are corresponding market shares and profits. The left-most column describes the duopoly type. For instance, $(h=N P, l=F P)$ represents the mixed duopoly since the NP firm delivers high quality $(h)$ and the FP firm delivers low quality $(l)$.

1968) reports that donations to art performing groups stand for between one-third and one-half of their income. 
We can see that the market shares of the firms catering to the upper and lower end of the market are very similar across different combinations of ownership types: $0.52-0.54$ for the top product and $0.26-0.27$ for the low quality product. There are, however, large differences in qualities produced and prices charged. In the FP duopoly the top quality (0.12) is significantly lower when compared to the other two cases (0.21 in the NP duopoly and 0.23 in the mixed duopoly). Surprisingly, the competition between a FP and NP firm leads to a higher top quality than in the case of two NP firms. This can be explained by the attempt of the top firm to decrease its quality when the low quality increases. ${ }^{19}$ I.e. if the competition is tougher (as in the case of two NP firms, or when firms decide simultaneously compared to sequentially), the top quality is lower so as to offer more competitive qualityprice bundles and in this way to protect its market share. If the NP firm competes with a FP firm, the NP firm does not decrease quality as much as in the case of two NP firms since the low quality offered by the FP rival is lower than the low quality produced by the NP competitor. The FP firm, in addition, maximizes profit, whaich means that the competition for the marginal consumer is not as tough as in case of the zero-profit competitor.

\footnotetext{
${ }^{19}$ This is true for sequential choice when the NP competes with the FP.
} 


\section{Discussion}

In the preceding sections, I analyzed the coexistence of one NP and one FP firm within a market. The two firms choose simultaneously or sequentially qualities and prices. The choice of each firm affects its own but also the rival's market share. In the following subsections I discuss several generalizations and extensions of the mixed duopoly model discussed in Section 2.2.8.

\subsection{Inefficiency in the NP firm}

It is often argued that tax-exemption, donations, and lack of owners lower pressure on the NP's competitiveness and create an opportunity for inefficiency in NP firms (Newhouse 1970, Rose-Ackerman 1996). To analyze the impact of NP inefficiency on $(q, p)$-pairs offered by the FP and NP firm I assume the subsidy, $s$, to be negative. In such case the NP firm has a comparative disadvantage introduced through higher production costs.

In reality, the NP firm even with $s \geq 0$ might be inefficient. For instance, take donations and tax exemption that could decrease production costs by 0.7. Due to an inefficiency in the NP firm, the effect of these advantages might be only 0.9 .

In Table 3 I compare the equilibrium with $s=0.3$ to equilibria with $s \in$ $\langle-0.3,0.0\rangle$. 


\begin{tabular}{|c|c|c|c|c|c|c|c|c|}
\hline $\mathrm{s}$ & $q_{n}$ & $q_{f}$ & $p_{n}$ & $p_{f}$ & $t_{n}$ & $t_{f}$ & $\Pi_{n}$ & $\Pi_{f}$ \\
\hline 0.3 & 0.3388 & 0.0328 & 0.1568 & 0.0076 & 0.5124 & 0.2562 & 0 & 0.0009 \\
0.0 & 0.2299 & 0.0337 & 0.1019 & 0.0075 & 0.5190 & 0.2595 & 0 & 0.0008 \\
-0.1 & 0.2065 & 0.0340 & 0.0900 & 0.0074 & 0.5215 & 0.2607 & 0 & 0.0008 \\
-0.2 & 0.1868 & 0.0343 & 0.0799 & 0.0073 & 0.5241 & 0.2620 & 0 & 0.0007 \\
-0.3 & 0.1699 & 0.0347 & 0.0713 & 0.0073 & 0.5269 & 0.2634 & 0 & 0.0007 \\
\hline
\end{tabular}

Table 3: Inefficiency in the NP firm

In equilibrium the NP firm delivers the top quality even in the case of inefficient NP production. ${ }^{20}$ This quality is, however, lower than in case of efficient production. Due to the zero-profit constraint the NP price decreases correspondingly. The NP firm thus pushes the FP firm down to less profitable consumers. The possibilities for positive profits shrink and the FP firm is forced to offer a more competitive product. The FP firm increases quality and decreases price. The market share of the FP firm, thus, slightly raises and its profit declines.

\subsection{Market size}

The effect of market size (which I derive in Section 6), $a$, is symmetric. Both qualities and prices are increasing in $a$. Market shares are independent on $a$. If the market size is increased, numbers of consumers with a certain taste are increased equally and the proportion of high to low quality consumers stays the same. The independence of firms' market shares of the market size would be, therefore, preserved even under a different distribution of tastes

\footnotetext{
${ }^{20}$ The opposite is not true even for inefficiency close to one. Should the FP firm produce the top quality the NP would leave the market, i.e. produce zero quality.
} 
for quality.

\subsection{Mixed duopoly - modified sequential game}

In mixed duopoly - sequential choice (Section 2.2.9), I assumed that the NP firm maximizes quality in both stages such that the zero-profit constraint is satisfied. In the first stage its control variable is quality and in the second stage its price. It might be reasonable to take an alternative sequential problem where the NP firm maximizes quality first (without explicit constraints) and then chooses its price just to cover its fixed costs (in what follows I use the term 'modified sequential game'). These two setups are, indeed, different since in the first case the NP firm maximizes quality with respect to both its variables, quality, and price, while in the modified sequential game it maximizes quality only with respect to quality.

Thus, while the FP firm maximizes profit in both stages, the NP firm first maximizes quality and then it sets price such that the zero-profit constraint is satisfied.

Starting with the second stage, the FP firm chooses a price that maximizes its profit (i.e. sets $M R=0$ ) given $q_{n}, q_{f}$ and $p_{n}$. Its pricing strategy follows the pricing strategy of the NP firm $\left(p_{f}=\frac{p_{n} q_{f}}{2 q_{n}}\right)$. Thus, if the NP firm charges a higher price then the FP firm can also charge a higher price to gain consumers with a higher willingness to pay. On the other hand if the NP charges a lower 
price, then the FP has to charge a proportionately lower price. ${ }^{21}$

The NP firm, given $q_{n}, q_{f}$ and $p_{f}$, charges price $p_{n}$ which satisfies the zeroprofit constraint. There are two such prices since the constraint is quadratic in $p_{n}$. With a lower price, the NP firm produces lower quality and enlarges its market share. With a higher price, it becomes attractive to a smaller number of consumers. On the other hand, these consumers are willing to pay more and the firm even might be able to increase quality. The smaller market share is thus compensated for by higher price and the NP firm is still able to cover its production costs.

In the first stage of the modified sequential game, the NP firm maximizes quality given $p_{n}^{*}\left(q_{n}, q_{f}\right), p_{f}^{*}\left(q_{n}, q_{f}\right)$ and $q_{f}$. The FP firm chooses quality to maximize its profit.

In the modified sequential game, surprisingly, the coexistence of the two firms is not possible in equilibrium. The nonprofit firm chooses monopoly quality, $\frac{1}{4(1-s)}$. Such $q_{n}$ ensures that the FP firm stays out of the market. This is indeed optimal for the NP firm since with the entry of the FP firm it would need to decrease its quality which is against its goal to maximize quality. ${ }^{22}$ The fact that the FP firm cannot profitably enter is striking since the NP firm satisfies only one half of the market. ${ }^{23}$ From the FP firm point of view

\footnotetext{
${ }^{21}$ For computational details see Section 6 .

${ }^{22}$ This can be checked differentiating the NP's best response to the FP's quality. The derivative is decreasing; see Section 6 for details.

${ }^{23}$ For instance in the Shaked and Sutton (1982) model with zero costs and symmetric producers the whole market is satisfied.
} 
the NP firm is too tough a rival to compete with since it has zero profit.

In the modified sequential game, the coexistence is not possible even if we keep the costs of quality equal to zero up to a certain point $(d>0)$ and then let them grow quadratically. This is curious since zero costs for qualities up to $d$ should allow the FP firm to enter and even make a positive profit. This is, indeed, the result of the simultaneous game, where the equilibrium for $s=0$ and $d=0.25$ is $\left(q_{n}, q_{f}, p_{n}, p_{f}\right)=(0.5659,0.2500,0.1776,0.0392)$. The corresponding market shares and profits are $t_{n}=0.5621, t_{f}=0.2810$, and $\Pi_{n}=0.0000, \Pi_{f}=0.0110$.

The shifted quadratic cost function allows the quality of 0.25 to be produced at zero cost, thus the NP firm can produce significantly higher quality than previously (Section 2.2.9). Consumers' willingness to pay increases. The NP firm can charge a higher price and subsequently increase its quality even further (0.5659 compared to 0.2344 for the case of a non-shifted quadratic cost function). The FP firm produces a quality of 0.25 at zero cost. Thus it can decrease its price to gain larger market share. The profit of the NP firm increases to 0.0110 (from 0.0008).

For a shifted cubic function of the form $c(q)=(q-d)^{3}+d^{3}$, where $d=$ 0.25 , the results are reversed compared to the case of the shifted quadratic cost function. There exists an equilibrium with both firms in the market in the modified sequential game but such an equilibrium does not exist in the simultaneous game. 


\section{Conclusion}

The coexistence of NP and FP firms within an industry is common in many service fields. There is, however, a lack of theoretical and empirical studies that focus on interaction between firms that have adopted these different ownership forms. In this paper, I develop a simple model of competition between one NP and one FP firm. The two firms have different objectives and face different constraints. I derive optimal quality-price bundles chosen by the two firms and their market shares.

The present model extends models of vertical differentiation to the possibility of one firm being NP. It also extends the research on the cross-sectoral competition between NP and FP firms in that I focus on quality as the strategic variable.

Under the assumption of heterogeneous tastes for quality the quality maximizing NP firm always produces the top quality in the market. The NP firm sells its product to the upper segment of the market and serves slightly more than one half of it. The FP firm serves consumers with a lower willingness to pay and its market share is slightly above one quarter.

Since the NP firm can receive subsidies, their impact on equilibrium outcomes is discussed. Subsidies decrease production costs of the NP firm and cause an increase in quality and price of the NP product. The FP firm can decrease the quality and price of its product in turn and its profit increases. Market 
shares of both firms decline. The total market share served by the two firms, therefore, decreases with the subsidy given to the NP firm.

The models presented here are based on specific assumptions. Although Section 3 discusses some extensions (e.g. inefficiency in the NP firm) other interesting questions remain unanswered.

First, in the present paper only fixed production costs are assumed: firms have to attract a sufficient market share to cover the fixed costs of the quality produced. Incorporating variable production costs would make the model better suited for the analysis of the coexistence of FP and NP firms in health care and education, where the variable cost component is non-negligible.

Second, in the present models I assumed that the NP firm maximizes quality. Quality maximization by the NP firm is a useful benchmark case since it illustrates how large the product differentiation could be if two competing firms have different objectives. In reality, NP firms have more complicated objectives such as a combination of quality and market share maximization. Also, I assumed that consumers are identical in wealth. With wealth differences it would be possible to explore objectives of the NP firm such as serving indigents, a quid pro quo that constitutes a major rationale for various tax and regulatory breaks bestowed on NPs.

Third, in the analysis I put aside the possibility of entry by an additional firm. In the NP monopoly the entry of another firm, whether NP or FP, is 
not possible. It would be interesting to explore whether a third firm could enter the mixed duopoly or whether an entering NP firm could push the FP firm out of the market.

\section{References}

Clotfelter, C.T. (1992). Who Benefits from the Nonprofit Sector? University of Chicago Press, Chicago.

Facchina, B., Showell, E.A., and Stone, J.E. (1993). Privileges and exemptions enjoyed by nonprofit organizations. University of San Francisco Law Review 28, 85-121.

Grabowski, D.C. and Hirth, R.A. (2003). Competitive spillovers across nonprofit and for-profit nursing homes. Journal of Health Economics 22, 1-22.

Hansmann, H. (1980). The role of nonprofit enterprise. Yale Law Journal 89, 835-901.

Hansmann, H. (1981). Nonprofit enterprise in the performing arts. The Bell Journal of Economics 12, 341-361.

Hirth, R.A. (1999). Consumer information and competition between nonprofit and for-profit nursing homes. Journal of Health Economics 18, 219240. 
Leete, L. (2001). Whither the nonprofit differential? Estimates from the 1990 Census. Journal of Labor Economics 19(1), 136-170.

Kessler, D. and McClellan, M.B. (2001). The effects of hospital ownership on medical productivity. NBER Working Paper No. 8537.

Newhouse, J.P. (1970). Toward a theory of nonprofit institutions: An economic model of a hospital. American Economic Review 60(1), 64-74.

Ortmann, A. and Schlessinger, M. (2003). Trust, repute, and the role of nonprofit enterprise. In The Study of Nonprofit Enterprise: Theories and Approaches, eds. H.K. Anheier and A. Ben-Ner. New York, Kluwer.

Rose-Ackerman, S. (1996). Altruism, nonprofits, and economic theory. Journal of Economic Literature 34, 701-728.

Shaked, A. and Sutton, J. (1982). Relaxing price competition through product differentiation. Review of Economic Studies 49, 3-13.

Weisbrod, B. (1975). Toward a theory of the voluntary nonprofit sector in a three-sector economy. In Altruism, Morality, and Economic Theory, ed. E.S. Phelps. New York, Russell Sage Foundation.

Weisbrod, B. (1988). The Nonprofit Economy. Harvard University Press, Cambridge.

Williamson, O.E. (1963). Managerial discretion and business behavior. Amer- 
ican Economic Review 53(5), 1032-1056.

\section{Appendix}

\subsection{FP and NP monopoly}

FP: First order conditions

$\frac{p_{f}^{2}}{q_{f}^{2}}-2 q_{f}=0$

$1-\frac{2 p_{f}}{q_{f}}=0$.

NP: First order conditions

$1-\mu\left(\frac{p_{n}}{q_{n}^{2}} p_{n}-2(1-s) q_{n}\right)=0$

$0-\mu\left(1-\frac{2 p_{n}}{q_{n}}\right)=0$

$\left(1-\frac{p_{n}}{q_{n}}\right) p_{n}-(1-s) q_{n}^{2}=0$.

\begin{tabular}{|c|c|c|c|}
\hline $\mathrm{b}$ & $q_{n}$ & $p_{n}$ & $t_{n}$ \\
\hline 0.6 & 0.1389 & 0.0231 & 0.8333 \\
0.7 & 0.2041 & 0.0586 & 0.7143 \\
0.8 & 0.2344 & 0.0879 & 0.6250 \\
0.9 & 0.2469 & 0.1097 & 0.5556 \\
1.0 & 0.2500 & 0.1250 & 0.5000 \\
\hline
\end{tabular}

\subsection{FP duopoly - simultaneous choice}

The general formulation of the problem from Section 2.2.1 is as follows:

$F P_{h}: \operatorname{Max}_{q_{h}, p_{h}} a\left(1-\frac{p_{h}-p_{l}}{q_{h}-q_{l}}\right) p_{h}-q_{h}^{2}$

$F P_{l}: \operatorname{Max}_{q_{l}, p_{l}} a\left(\frac{p_{h}-p_{l}}{q_{h}-q_{l}}-\frac{p_{l}}{q_{l}}\right) p_{l}-q_{l}^{2}$, 
where the positive parameter $a$ represents market size. The first order conditions are the following:

$p_{h}-\left(q_{h}-q_{l}+p_{l}\right) / 2=0$

$a p_{h} \frac{p_{h}-p_{l}}{\left(q_{h}-q_{l}\right)^{2}}-2 q_{h}=0$

$p_{l}-\frac{p_{h} q_{l}}{2 q_{h}}=0$

$a p_{l}\left(\frac{p_{h}-p_{l}}{\left(q_{h}-q_{l}\right)^{2}}+\frac{p_{l}}{q_{l}^{2}}\right)-2 q_{l}=0$.

From the first and third equation we can write prices as functions of qualities $p_{h}=\frac{2 q_{h}\left(q_{h}-q_{l}\right)}{4 q_{h}-q_{l}}, p_{l}=\frac{q_{l}\left(q_{h}-q_{l}\right)}{4 q_{h}-q_{l}}$,

where $4 q_{h} \neq q_{l}$. Plugging these expressions into the second and fourth equations we get the following system of two equations and two variables, $q_{h}$ and $q_{l}$ :

$a\left(2 q_{h}-q_{l}\right)=\left(4 q_{h}-q_{l}\right)^{2}$

$a q_{h}^{2}=2 q_{l}\left(4 q_{h}-q_{l}\right)^{2}$.

In equilibrium,

$q_{h}=\frac{a(26+7 \sqrt{2})}{289}, q_{l}=\frac{a(19-6 \sqrt{2})}{289}, p_{h}=\frac{2 a(364+387 \sqrt{2})}{4913(5+2 \sqrt{2})}, p_{l}=\frac{a(-23+250 \sqrt{2})}{4913(5+2 \sqrt{2})}$,

$t_{h}=\frac{2(364+387 \sqrt{2})}{1479+1343 \sqrt{2}}, t_{l}=\frac{2272+5169 \sqrt{2}}{11985+16643 \sqrt{2}}$, and

$\Pi_{h}=\frac{2 a^{3}(366315+206587 \sqrt{2})}{83521(751+569 \sqrt{2})}, \Pi_{l}=\frac{a^{2}(1720161-686644 \sqrt{2})}{83521(7441+6305 \sqrt{2})}$.

\subsection{FP duopoly - sequential choice}

Second stage - the choice of optimal prices

First order conditions to the problem in Section 2.2.2 are the following:

$p_{h}-\left(q_{h}-q_{l}+p_{l}\right) / 2=0$ 
$p_{l}-\frac{p_{h} q_{l}}{2 q_{h}}=0$.

Solving the system we get $p_{h}^{*}\left(q_{h}, q_{l}\right)=\frac{2 q_{h}\left(q_{h}-q_{l}\right)}{4 q_{h}-q_{l}}$ and $p_{l}^{*}\left(q_{h}, q_{l}\right)=\frac{q_{l}\left(q_{h}-q_{l}\right)}{4 q_{h}-q_{l}}$.

First stage - the choice of optimal qualities

First order conditions are the following:

$-\frac{32 a q_{h}^{2}\left(q_{h}-q_{l}\right)}{\left(4 q_{h}-q_{l}\right)^{3}}+\frac{4 a q_{h}^{2}+8 a q_{h}\left(q_{h}-q_{l}\right)}{\left(4 q_{h}-q_{l}\right)^{2}}=2 q_{h}$

$\frac{a q_{h}\left(q_{h}-q_{l}\right)-a q_{h} q_{l}}{\left(4 q_{h}-q_{l}\right)^{2}}+\frac{2 a q_{h} q_{l}\left(q_{h}-q_{l}\right)}{\left(4 q_{h}-q_{l}\right)^{3}}=2 q_{l}$.

\subsection{NP duopoly - simultaneous choice}

First order conditions to the maximization problem (2.2.5) are

$1+\mu\left(-2 q_{h}+\frac{a p_{h}\left(p_{h}-p_{l}\right)}{\left(q_{h}-q_{l}\right)^{2}}\right)=0$

$\mu\left(a\left(1-\frac{p_{h}-p_{l}}{q_{h}-q_{l}}\right)-\frac{a p_{h}}{q_{h}-q_{l}}\right)=0$

$-q_{h}^{2}+a p_{h}\left(1-\frac{p_{h}-p_{l}}{q_{h}-q_{l}}\right)=0$

$1+\nu\left(a p_{l}\left(\frac{p_{h}-p_{l}}{\left(q_{h}-q_{l}\right)^{2}}+\frac{p_{l}}{q_{l}^{2}}\right)-2 q_{l}\right)=0$

$\nu\left(a p_{l}\left(-\frac{1}{q_{h}-q_{l}}-\frac{1}{q_{l}}\right)+a\left(\frac{p_{h}-p_{l}}{q_{h}-q_{l}}-\frac{p_{l}}{q_{l}}\right)\right)=0$

$a p_{l}\left(\frac{p_{h}-p_{l}}{q_{h}-q_{l}}-\frac{p_{l}}{q_{l}}\right)-q_{l}^{2}=0$.

From the first and fourth condition we see that $\mu$ and $\nu$ are non-zero. Therefore the second and fifth equation can be rewritten as

$a\left(1-\frac{p_{h}-p_{l}}{q_{h}-q_{l}}\right)-\frac{a p_{h}}{q_{h}-q_{l}}=0$

$a p_{l}\left(\frac{1}{q_{h}-q_{l}}+\frac{1}{q_{l}}\right)-a\left(\frac{p_{h}-p_{l}}{q_{h}-q_{l}}-\frac{p_{l}}{q_{l}}\right)=0$.

From these two equation we have

$p_{h}=\frac{2 q_{h}\left(q_{h}-q_{l}\right)}{4 q_{h}-q_{l}}$ and $p_{l}=\frac{q_{l}\left(q_{h}-q_{l}\right)}{4 q_{h}-q_{l}}$.

For $q_{h}$ and $q_{l}$ non-zero and $4 q_{h} \neq q_{l}$ FOCs numbers 3 and 6 can be then 
simplified to

$4 a\left(q_{h}-q_{l}\right)=\left(4 q_{h}-q_{l}\right)^{2}$

$a q_{h}\left(q_{h}-q_{l}\right)=q_{l}\left(4 q_{h}-q_{l}\right)^{2}$.

The system can be solved for $q_{h}$ and $q_{l}$ and the equilibrium is

$\left(q_{h}, q_{l}, p_{h}, p_{l}, t_{h}, t_{l}, \Pi_{h}, \Pi_{l}\right)=\left(\frac{16 a}{75}, \frac{4 a}{75}, \frac{32 a}{375}, \frac{4 a}{375}, \frac{8}{15}, \frac{4}{15}, 0,0\right)$.

\subsection{NP duopoly - sequential choice}

The choice of price is

$N P_{h}: \max _{p_{h}} q_{h}$ s.t. $\left(1-\frac{p_{h}-p_{l}}{q_{h}-q_{l}}\right) p_{h}=q_{h}^{2}$

$N P_{l}: \max _{p_{l}} q_{l}$ s.t. $\left(\frac{p_{h}-p_{l}}{q_{h}-q_{l}}-\frac{p_{l}}{q_{l}}\right) p_{l}=q_{l}^{2}$.

First order conditions are

$\mu\left(a-a \frac{p_{h}-p_{l}}{q_{h}-q_{l}}-a \frac{p_{h}}{q_{h}-q_{l}}\right)=0$

$a\left(1-\frac{p_{h}-p_{l}}{q_{h}-q_{l}}\right) p_{h}=q_{h}^{2}$

$\nu\left(a \frac{p_{h}-2 p_{l}}{q_{h}-q_{l}}-a \frac{p_{l}}{q_{l}}\right)=0$

$a\left(\frac{p_{h}-p_{l}}{q_{h}-q_{l}}-\frac{p_{l}}{q_{l}}\right) p_{l}=q_{l}^{2}$.

Focusing on the case when $\mu \neq 0$ and $\nu \neq 0$, the optimal prices are

$p_{h}^{*}\left(q_{h}, q_{l}\right)=\frac{2 q_{h}\left(q_{h}-q_{l}\right)}{4 q_{h}-q_{l}}$ and $p_{l}^{*}\left(q_{h}, q_{l}\right)=\frac{q_{l}\left(q_{h}-q_{l}\right)}{4 q_{h}-q_{l}}$.

The choice of quality is

$N P_{h}: \max _{q_{h}} q_{h}$ s.t. $4\left(q_{h}-q_{l}\right)=\left(4 q_{h}-q_{l}\right)^{2}$

$N P_{l}: \max _{q_{l}} q_{l}$ s.t. $q_{l}\left(q_{h}-q_{l}\right)=q_{2}\left(4 q_{h}-q_{l}\right)^{2}$.

First order conditions are

$1+\kappa\left(4 a-8\left(4 q_{h}-q_{l}\right)\right)=0$ 
$4 a\left(q_{h}-q_{l}\right)-\left(4 q_{h}-q_{l}\right)^{2}=0$

$1+\lambda\left(-a q_{h}-\left(4 q_{h}-q_{l}\right)^{2}+2\left(4 q_{h}-q_{l}\right) q_{l}\right)=0$

$a q_{h}\left(q_{h}-q_{l}\right)-\left(4 q_{h}-q_{l}\right)^{2} q_{l}=0$. The unique solution of the system above is $q_{h}=\frac{16 a}{75}, q_{l}=\frac{4 a}{75}, \kappa=\frac{5}{12 a}$, and $\lambda=\frac{125}{96 a^{2}}$. Using optimal $q_{h}$ and $q_{l}$ we can derive equilibrium prices, market shares, and profits:

$p_{h}=\frac{32 a}{375}, p_{l}=\frac{4 a}{375}, t_{h}=\frac{8}{15}, t_{l}=\frac{4}{15}$, and $\Pi_{h}=\Pi_{l}=0$.

\subsection{Mixed duopoly - simultaneous choice}

First order conditions to the problem are

$1+\mu\left(a \frac{p_{n}-p_{f}}{\left(q_{n}-q_{f}\right)^{2}} p_{n}-2(1-s) q_{n}\right)=0$

$\mu\left(a-a \frac{p_{n}-p_{f}}{q_{n}-q_{f}}-a p_{n} \frac{1}{q_{n}-q_{f}}\right)=0$

$a\left(1-\frac{p_{n}-p_{f}}{q_{n}-q_{f}}\right) p_{n}-(1-s) q-n^{2}=0$

$a \frac{p_{n}-p_{f}}{q_{n}-q_{f}}-a \frac{p_{f}}{q_{f}}-a \frac{p_{f}}{q_{n}-q_{f}}-a \frac{p_{f}}{q_{f}}=0$

$a \frac{p_{n}-p_{f}}{\left(q_{n}-q_{f}\right)^{2}} p_{f}+a \frac{p_{f}}{q_{f}^{2}} p_{f}-2 q_{f}=0$.

From the first equation $\mu \neq 0$, thus the second equation can be rewritten as $a-a \frac{p_{n}-p_{f}}{q_{n}-q_{f}}-a p_{n} \frac{1}{q_{n}-q_{f}}=0$.

This equation together with the fourth equation implies

$p_{n}=\frac{2 q_{n}\left(q_{n}-q_{f}\right)}{4 q_{n}-q_{f}}, p_{f}=\frac{q_{f}\left(q_{n}-q_{f}\right)}{4 q_{n}-q_{f}}$

(for $q_{n} \neq q_{f}, q_{f} \neq 0$, and $4 q_{n} \neq q_{f}$.) The third and fifth equations then become

$4 a\left(q_{n}-q_{f}\right)=(1-s)\left(4 q_{n}-q_{f}\right)^{2}$

$a q_{n}^{2}=2 q_{f}\left(4 q_{n}-q_{f}\right)^{2}$. 
There are two solutions to this system of two equations with two unknowns:

Solution 1

$\left(q_{n}, q_{f}\right)=\left(\frac{8 a(170+71 \sqrt{2(1+s)}+s(-26+\sqrt{2(1+s)}))}{(1-s)(97-s)^{2}}, \frac{4 a(99+s-14 \sqrt{2(1+s)})}{(97-s)^{2}}\right)$

Solution 2

$\left(q_{n}, q_{f}\right)=\left(\frac{8 a(170-71 \sqrt{2(1+s)}-s(26+\sqrt{2(1+s)}))}{(1-s)(97-s)^{2}}, \frac{4(99 a+a s+14 a \sqrt{2(1+s)})}{(97-s)^{2}}\right)$.

Solution 2 gives negative profit to the FP firm so the FP firm would not enter the market. The only equilibrium is, therefore, Solution 1 . In the equilibrium the prices, market shares, and profits of the two competitors are

$p_{n}=\frac{16 a\left(241+s^{2}+156 \sqrt{2(1+s)}+s(46-12 \sqrt{2(1+s)})(170+71 \sqrt{2(1+s)}+s(-26+\sqrt{2(1+s)}))\right.}{(1-s)(97-s)^{3}(13-s+6 \sqrt{2(1+s)})}$

$p_{f}=\frac{4 a(99+s-14 \sqrt{2(1+s)})\left(241+s^{2}+156 \sqrt{2(1+s)}+s(46-12 \sqrt{2(1+s)})\right)}{(97-s)^{3}(13-s+6 \sqrt{2(1+s)})}$

$t_{n}=\frac{4(170+71 \sqrt{2(1+s)}+s(-26+\sqrt{2(1+s)}))}{(97-s)(13-s+6 \sqrt{2(1+s)})}$

$t_{f}=\frac{2(170+71 \sqrt{2(1+s)}+s(-26+\sqrt{2(1+s)}))}{(97-s)(13-s+6 \sqrt{2(1+s)})}$

$\Pi_{n}=0$

$\left.\Pi_{f}=\frac{z}{(97-s)^{4}(13-s+6 \sqrt{2(1+s)})^{2}}\right)$,

where $z=8 a^{2}(1844112+1591649 \sqrt{2(1+s)}+s(1515040-196004 \sqrt{2(1+s)})+$

$s^{4}(-80+\sqrt{2(1+s)})+4 s^{3}(-5512+327 \sqrt{2(1+s)})+$

$2 s^{2}(-175520+48019 \sqrt{2(1+s)})$.

For specific values of parameters $a$ and $s$ the equilibrium is 


\begin{tabular}{|c|c|c|c|c|c|c|c|c|}
\hline \multicolumn{9}{|l|}{$a=1$} \\
\hline $\mathrm{S}$ & $q_{n}$ & $q_{f}$ & $p_{n}$ & $p_{f}$ & $t_{n}$ & $t_{f}$ & $\Pi_{n}$ & $\Pi_{f}$ \\
\hline 0.0 & 0.2299 & 0.0337 & 0.1019 & 0.0075 & 0.5190 & 0.2595 & 0 & 0.0008 \\
\hline 0.1 & 0.2583 & 0.0334 & 0.1162 & 0075 & 0.5167 & 0.2583 & 0 & 0.0008 \\
\hline 0.2 & 0.2936 & 0.0331 & 0.1340 & 0.0076 & 0.5145 & 0.2572 & 0 & 0.0008 \\
\hline 0.3 & 3388 & 0.0328 & 0.1 & 0076 & 0.5124 & 0.2562 & 0 & 0.0009 \\
\hline 0.4 & 0.3988 & 0.0326 & 0.18691 & 0.0076 & 0.5104 & 0.2552 & 0 & 0.0009 \\
\hline 0.5 & 4825 & 0.0323 & 0.2289 & 0.0077 & 0.5085 & 0.2543 & 0 & 0.0009 \\
\hline 0.6 & 0.6079 & 0.0321 & 0.2918 & 0.0077 & 0.5067 & 0.2533 & 0 & 0.0009 \\
\hline 0.7 & 0.8167 & 0.0319 & 0.3963 & 0.0077 & 0.5049 & 0.2525 & 0 & 0.0009 \\
\hline 0.8 & 1.2337 & 0.0317 & 0.6049 & 0.0078 & 0.5032 & 0.2516 & 0 & 0.0010 \\
\hline 0.9 & 2.4841 & 0.0314 & 1.2302 & 0.0078 & 0.5016 & 0.2508 & 0 & 0.0010 \\
\hline \multicolumn{9}{|l|}{$a=2$} \\
\hline 0.0 & 0.4598 & 0.0673 & 0.2037 & 0.0149 & 0.5190 & 0.2595 & 0 & 0.0032 \\
\hline 0.1 & 0.5166 & 0.0667 & 0.2324 & 0.0150 & 0.5167 & 0.2583 & 0 & 0.0033 \\
\hline 0.3 & 0.6775 & 0.0656 & 0.3135 & 0.0152 & 0.5124 & 0.2562 & 0 & 0.0035 \\
\hline 0.5 & 0.9651 & 0.0646 & 0.4579 & 0.0153 & 0.5085 & 0.2543 & 0 & 0.0036 \\
\hline
\end{tabular}

\subsection{Mixed duopoly - sequential choice}

For the choice of prices, firms solve

NP: $\max _{p_{n}} q_{n}$ s.t. $a\left(1-\frac{p_{n}-p_{f}}{q_{n}-q_{f}}\right) p_{n}=(1-s) q_{n}^{2}$

FP: $\max _{p_{f}} a\left(\frac{p_{n}-p_{f}}{q_{n}-q_{f}}-\frac{p_{f}}{q_{f}}\right) p_{f}-q_{f}^{2}$.

First order conditions are

$\mu\left(a-a \frac{p_{n}-p_{f}}{q_{n}-q_{f}}-a \frac{p_{n}}{q_{n}-q_{f}}\right)=0$

$a\left(1-\frac{p_{n}-p_{f}}{q_{n}-q_{f}}\right) p_{n}=(1-s) q_{n}^{2}$

$p_{f}-\frac{p_{n} q_{f}}{2 q_{n}}=0$.

Focusing on the case when the NP's constraint is binding $(\mu \neq 0)$ the optimal prices are $p_{n}=\frac{2 q_{n}\left(q_{n}-q_{f}\right)}{4 q_{n}-q_{f}}, p_{f}=\frac{q_{f}\left(q_{n}-q_{f}\right)}{4 q_{n}-q_{f}}\left(\right.$ for $q_{n} \neq q_{f}, q_{f} \neq 0$, and $4 q_{n} \neq q_{f}$ ). Then the optimization problems in the first stage (the choice of quality) 
become

NP: $\max _{q_{n}} q_{n}$ s.t. $4 a\left(q_{n}-q_{f}\right)=(1-s)\left(4 q_{n}-q_{f}\right)^{2}$

FP: $\max _{q_{f}} \frac{a q_{n} q_{f}\left(q_{n}-q_{f}\right)}{\left(4 q_{n}-q_{f}\right)^{2}}-q_{f}^{2}$. First order conditions are the following

$1-\kappa\left(4 a-8(1-s)\left(4 q_{n}-q_{f}\right)\right)=0$

$4 a\left(q_{n}-q_{f}\right)-(1-s)\left(4 q_{n}-q_{f}\right)^{2}=0$

$\frac{\left(a q_{n}\left(q_{n}-q_{f}\right)-a q_{n} q_{f}\right)\left(4 q_{n}-q_{f}\right)^{2}+2 a q_{n} q_{f}\left(q_{n}-q_{f}\right)\left(4 q_{n}-q_{f}\right)}{\left(4 q_{n}-q_{f}\right)^{4}}-2 q_{f}=0$.

The numerical solution to this system gives for $a=1$ and $s=0$

$\left(q_{n}, q_{f}, p_{n}, p_{f}\right)=(0.2344,0.0272,0.1067,0.0062)$. The corresponding market shares and profits are $t_{n}=0.5149, t_{f}=0.2575$, and $\Pi_{n}=0, \Pi_{f}=0.0009$.

\subsection{Mixed duopoly - modified sequential game}

For the choice of prices, first order conditions are

$\mathrm{NP}: a\left(1-\frac{p_{n}-p_{f}}{q_{n}-q_{f}}\right) p_{n}=(1-s) q_{n}^{2}$

FP: $a\left(\frac{p_{n}-p_{f}}{q_{n}-q_{f}}-\frac{p_{f}}{q_{f}}\right)-a \frac{1}{q_{n}-q_{f}} p_{f}-a \frac{1}{q_{f}} p_{f}=0$.

Optimal prices are

$p_{n}=\frac{a q_{n}\left(q_{n}-q_{f}\right) \pm q_{n} \sqrt{\left(a\left(q_{n}-q_{f}\right)\right)^{2}-2 a(1-s) q_{n}\left(q_{n}-q_{f}\right)\left(2 q_{n}-q_{f}\right)}}{a\left(2 q_{n}-q_{f}\right)}$

$p_{f}=\frac{q_{f}}{2 q_{n}} \frac{a q_{n}\left(q_{n}-q_{f}\right) \pm q_{n} \sqrt{\left(a\left(q_{n}-q_{f}\right)\right)^{2}-2 a(1-s) q_{n}\left(q_{n}-q_{f}\right)\left(2 q_{n}-q_{f}\right)}}{a\left(2 q_{n}-q_{f}\right)}$.

Both prices are positive. The following inequality has to be satisfied for prices to be real numbers:

$\left(a\left(q_{n}-q_{f}\right)\right)^{2}-2 a(1-s) q_{n}\left(q_{n}-q_{f}\right)\left(2 q_{n}-q_{f}\right) \geq 0$,

i.e. $q_{n} \in\left\langle\frac{a+2(1-s) q_{f}-\sqrt{\left(a+2(1-s) q_{f}\right)^{2}-16 a(1-s) q_{f}}}{8(1-s)}, \frac{a+2(1-s) q_{f}+\sqrt{\left(a+2(1-s) q_{f}\right)^{2}-16 a(1-s) q_{f}}}{8(1-s)}\right\rangle$.

From the upper and lower bound on $q_{n}$ the following bounds on $q_{f}$ follow: 
$\left(a+2(1-s) q_{f}\right)^{2}-16 a(1-s) q_{f} \geq 0$ i.e. $q_{f} \in\left\langle 0, \frac{3-2 \sqrt{2}}{2}\right\rangle \cup\left\langle\frac{3+2 \sqrt{2}}{2}, \infty\right)$.

With such $q_{f}$ the bound on $q_{n}$ becomes $q_{n} \in\left\langle\frac{2-\sqrt{2}}{4}, \frac{1}{4}\right\rangle$.

We are able to restrict $q_{f}$ to be from the interval $\left\langle 0, \frac{3-2 \sqrt{2}}{2}\right\rangle$ since $q_{f}<q_{n}$.

In the first stage, given $p_{n}^{*}\left(q_{n}, q_{f}\right)$ and $p_{f}^{*}\left(q_{n}, q_{f}\right)$ the two firms solve

NP: $\max _{q_{n}} q_{n}$

s.t. $q_{n} \in\left\langle\frac{a+2(1-s) q_{f}-\sqrt{\left(a+2(1-s) q_{f}\right)^{2}-16 a(1-s) q_{f}}}{8(1-s)}, \frac{a+2(1-s) q_{f}+\sqrt{\left(a+2(1-s) q_{f}\right)^{2}-16 a(1-s) q_{f}}}{8(1-s)}\right\rangle$

FP: $\max _{q_{f}} \frac{q_{n} q_{f}\left(a\left(q_{n}-q_{f}\right) \pm \sqrt{\left(a\left(q_{n}-q_{f}\right)\right)^{2}-2 a(1-s) q_{n}\left(q_{n}-q_{f}\right)\left(2 q_{n}-q_{f}\right)}\right)}{2\left(2 q_{n}-q_{f}\right)^{2}}-q_{f}^{2}$.

The NP firm maximizes its quality when it chooses

$q_{n}=\frac{a+2(1-s) q_{f}+\sqrt{\left(a+2(1-s) q_{f}\right)^{2}-16 a(1-s) q_{f}}}{8(1-s)}$.

This formula is, in fact, the NP's best response to the FP's quality. Differ-

entiating it with respect to $q_{f}$ we can see that $q_{n}$ is decreasing in $q_{f}$ :

$\frac{d q_{n}}{d q_{f}}=\frac{\sqrt{\left(a+2(1-s) q_{f}\right)^{2}-16 a(1-s) q_{f}}-6 a+4(1-s) q_{f}}{8 \sqrt{\left(a+2(1-s) q_{f}\right)^{2}-16 a(1-s) q_{f}}}<0$.

The denominator is positive while the numerator is always negative.

The FP's best response to the NP's quality follows from the first order condition. For the system of the two reaction functions there does not exist any solution that satisfies the conditions $q_{n} \neq q_{f}$ and $q_{f} \neq 0$. 
CERGE-EI

P.O.BOX 882 Politických vezòù 7

11121 Prague 1

Czech Republic http://www.cerge-ei.cz 